\title{
Infection with Toxoplasma gondii can promote chronic liver diseases in HIV-infected individuals
}

\author{
Ihor H. Hryzhak \\ Ivano-Frankivsk National Medical University (Ivano-Frankivsk, Ukraine); \\ Ivano-Frankivsk Regional Center for AIDS Prevention and Fight (Ivano-Frankivsk, Ukraine)
}

\begin{abstract}
Liver pathologies and infection with Toxoplasma gondii (Nicolle et Manceaux, 1908) are widespread among HIV-infected patients. However, a possible contribution of toxoplasmosis to the development of various forms of liver diseases in HIV-infected individuals has not yet been determined. This research is a retrospective cohort study. Medical cards of 907 HIV-positive patients, including 119 individuals who died, were studied. The patients were divided into two groups: 531 patients were seropositive to T. gondii and 376 seronegative. General liver pathology was more widespread among patients seropositive to T. gondii than in seronegative patients $(63.1 \pm 2.1 \%$ and $51.9 \pm 2.6 \%$, respectively, $\mathrm{p}<0.001)$. The association of seropositive to $T$. gondii with general liver pathology is weak both in the whole cohort (Pearson's contingency coefficient $\mathrm{C}=0.112)$, and among the deceased patients $(\mathrm{C}=0.228)$. Chronic HBV-HCV coinfection was more common in the seropositive than in seronegative individuals as it was found both in entire cohorts $(26.0 \pm 1.9 \%$ and $18.6 \pm 2.0 \%$, respectively, $\mathrm{p}=0.010)$ and in died patients $(31.0 \pm 5.5 \%$ and $14.6 \pm 5.1 \%$, respectively, $\mathrm{p}=0.041)$. Toxoplasma gondii had a weak role in distributing of $\mathrm{HBV}-\mathrm{HCV}$ coinfection between cohorts $(\mathrm{C}=0.187)$. In both cohorts in patients with chronic hepatitis, regardless of its etiology, there was no significant difference in alanine transaminase activity (ALT). Cirrhosis of the liver occurred 4.5 times more often in deceased seropositive patients than in the entire seropositive cohort (23.9 \pm 5.1 and 5.3 \pm 2.0 , respectively, $\mathrm{p}=0.0006)$ whereas it no significantly increased in seronegative cohort $(10.4 \pm 4.4$ against $4.8 \pm 1.1, p>0.05)$. In them $T$. gondii is weakly involved in cirrhosis formation $(\mathrm{C}=0.168)$. Thus, in HIV-infected patients, $T$. gondii is a weak nonspecific adjunct that supports chronic liver inflammation and progression of cirrhosis, regardless of etiology, but does not influence the degree of hepatitis activity. The increased prevalence of HBV-HCV coinfection in patients seropositive for $T$. gondii may be related to their risk factor behaviour associated with uncontrolled blood contacts.
\end{abstract}

Keywords: Toxoplasma gondii, HIV, infection, liver

Toxoplasma gondii (Nicolle et Manceaux, 1908) is an obligate intracellular parasitic protozoan eukaryote (an apicomplexan) that causes the infection disease toxoplasmosis (Dardé et al. 2011). It is estimated to affect at least one-third of the planet's population (Montoya and Liesenfeld 2004). This infection is generally asymptomatic but is associated with the 'burden' of different non-infectious human diseases (somatic, psychiatric, oncological and others) (Jones et al. 2001, Flegr et al. 2014, El-Rehim El-Henavy et al. 2015).

There are a few studies of toxoplasmic hepatitis in immunocompetent patients, which is accompanied by hepatomegaly, increasing rates of aspartate transaminase activity (AST), alanine transaminase activity (ALT), alkaline phosphatase activity (ALP) and gamma glutamyl transpeptidase activity (GGT), normal or increased levels of total bilirubin (Doğan et al. 2007, Atılla et al. 2015) and sometimes with symptoms of generalised toxoplasmosis (skin rash, retinochoroiditis, myositis) (Nunura et al. 2010). In many studies, it has been shown that chronic or latent toxoplasmosis makes a negative contribution to various liver diseases. For example, in Hangzhou City (China) the seropositive rate of anti-T. gondii IgG antibody among 1,200 patients with liver diseases was $24.0 \%$ but it was only $11.42 \%$ in healthy people. However, $T$. gondii seroprevalence did not depend on the exact diagnosis of these patients (liver cancer, hepatitis B virus infection, liver fibrosis, fatty degeneration of liver) (Jian-Feng et al. 2018). In non-pregnant healthy women with IgG to $T$. gondii there were higher levels of AST, ALT, ALP and GGT in blood serum compared with the control group of women (Nadwa and Muthear 2012).

On the other hand, chronic viral hepatitis promotes the activation of toxoplasmosis. Thus, the active co-infection with $T$. gondii was found in $33.3 \%$ of patients with chronic hepatitis B virus (HBV) infection and in $31.4 \%$ of patients with chronic hepatitis C (HCV) infection. It is suggested that the reactivation of latent infection with $T$. gondii 
occurs through exhaustion of cell-mediated immunity in these patients (Gazzinelli et al. 1992).

Parasitemia of T. gondii occurs in patients with chronic liver diseases much more frequently $(30 \%)$ than in patients without it (6\%). Furthermore, the high HCV viral load in patients with chronic HCV infection is significantly correlated with parasitemia of T. gondii (Nagwa et al. 2016) and high levels of anti-T. gondii IgG, but a correlation between the stage of liver fibrosis and the presence of antitoxoplasmic-IgM or IgG antibodies has not been found (ElNahas et al. 2014). However, other researchers think that there is an association between seropositive to $T$. gondii and fibrosis, inflammation and necrotic process in the liver of patients with chronic $\mathrm{HCV}$ infection. In these patients the albumin level, international normalised ratio and platelet count were significantly decreased (El-Rehim El-Henavy et al. 2015). The incidence of non-alcoholic fatty liver disease was higher in individuals seropositive to T. gondii than in seronegative individuals $(27.1 \%$ and $23.4 \%$, respectively, $\mathrm{p}<0.001)$. However, multivariant analysis revealed that infection with $T$. gondii was not an independent risk factor in liver diseases (Huang et al. 2018). A study performed among a northern Mexican population found that both seroprevalence of $T$. gondii and level of specific IgG did not differ significantly between patients with chronic liver diseases $(13.3 \%)$ and the control group (10.7\%). Therefore, researchers concluded that there is no association between seropositivity to $T$. gondii and any diagnosis of liver disease (Alvarado-Esquivel et al. 2011).

Immunocompromised individuals who are HIV-infected have a high risk of toxoplasmosis manifestation. Typically, these patients might have brain lesions, such as toxoplasmic encephalitis and myelopathy (Chaddha et al. 1999, Kung et al. 2011, García-García et al. 2015, Marra 2018) and the rate of cerebral toxoplasmosis in the general HIV-positive population is 3.5\% (Goïta et al. 2012). However, the burden of infection with $T$. gondii in HIV-infected patients is geographically variable and usually follows the prevalence of $T$. gondii in the general population (Veeranoot 2017, Vidal 2019). A low level of CD4 cells $(<100 /$ $\mathrm{mm}^{3}$ ) and a positive $T$. gondii serology are likely to predict the occurrence of toxoplasmic encephalitis within the following 12 months in $25.4 \%$ patients (Oksenhendler et al. 1994).

Extracerebral toxoplasmosis occurs in patients with more severe immunosuppression and a CD4+ lymphocyte mean count of $57 / \mathrm{mm}^{3}$. Its localisation includes eyes $(50 \%$ of patients), lungs $(26 \%)$, heart and pericardium $(3 \%)$, bone marrow $(3 \%)$, blood-(parasitemia with acute febrile syndrome) (3\%) and bladder (1\%). There were also isolated cases of toxoplasmosis infection of nasopharynx, skin, liver, lymph nodes and conus medullaris. Disseminated toxoplasmosis (at least two extracerebral visceral localisations) occurred in $11.5 \%$ of patients (Rabaud et al. 1994). There was a report about a patient with the AIDS and watery diarrhoea due to duodenitis, which was associated with toxoplasmic hepatitis, elevated serum ALP and lactate dehydrogenase activity (Bonacini et al. 1996).
In general, various liver diseases among HIV-infected patients are very common (Rodriguez-Mendez 2000). In the USA HBV infection (70-90\%) and HCV infection $(80 \%)$ were diagnosed in intravenous drug users (CDC 2017). Also, a wide spectrum of liver pathologies is found in deceased HIV-infected patients, such as chronic portal hepatitis $(80.0 \%)$, alcoholic hepatitis $(23.7 \%)$, fatty hepatosis $(7.5 \%)$, fatty degeneration of the liver $(73.7 \%)$, and liver cirrhosis (36.3\%) (Lytvynenko 2007). Various degrees of fibrosis and hepatocyte dysfunction occur in $\mathrm{HIV}$-infected individuals and contribute significantly to the mortality rate-which is $1.7 \%$ per 100 man-years (Qurishi et al. 2003, Castellares et al. 2008). It may be assumed that many opportunistic infections are reactivated before the death of HIV-infected patients. Cytomegalovirus (CMV), mycobacterium and $T$. gondii were found more frequently in autopsy liver tissues of HIV-positive patients than in biopsy samples of live patients (Trojan et al. 1998, Lang et al. 2005). Therefore, different liver pathologies and $T$. gondii might be combined in many patients. However, the consequences of interaction between them are not clear.

\section{MATERIALS AND METHODS}

Design of the study. A three-year retrospective cohort study was conducted at the Department of Infectious Diseases and Epidemiology of Ivano-Frankivsk National Medical University and at the Ivano-Frankivsk Regional Center for AIDS Prevention and Fight (Ukraine). It is part of a wider study "The course of infectious diseases on the background of concomitant pathology, combined chronic infections and invasions, correction of treatment", state registration number: 0112 U005012 (2019-2023). The medical data from 2013-2015 for 907 HIV-infected patients (men 58.3\%) with a mean age of $35.21 \pm 0.26$ years $(18-65$ years) were studied. IgG and IgM antibodies to Toxoplasma gondii and markers for hepatitis $\mathrm{B}$ and $\mathrm{C}$ (HBsAg, anti-HBc IgM and $\mathrm{IgG}$, anti-HCV total $\mathrm{Ig}$ ) in the blood were determined by enzyme-linked immunosorbent assay (test systems produced by DIAPROF-MED, Ukraine). Cytomegalovirus (CMV) and Epstein-Barr virus (EBV) DNA were determined by PCR.

According to the test results for $\operatorname{IgM}$ and $\operatorname{IgG}$ antibodies to T. gondii, the patients were divided into two cohorts: 531 seropositive individuals and 376 seronegative ones. Criteria for inclusion in the seropositive cohort were the presence of anti-Toxoplas$m a-\operatorname{IgG}$ or IgM or both IgG and IgM in the blood at the first test, regardless of the level of these antibodies. Some previously seronegative individuals were transferred from the seronegative to the seropositive cohort after the appearance of seroconversion (the appearance of specific IgM or IgG, or both IgG and IgM simultaneously). Patients who did not have $\operatorname{IgM}$ and $\operatorname{IgG}$ antibodies to T. gondii at the first test or during the next 3 years were included into the seronegative cohort. In both cohorts, patients with hepatitis $\mathrm{C}$ or HBV-HCV coinfection did not receive antiviral treatment for $\mathrm{HCV}$ infection for that period.

Statistical analysis. In both cohorts the percentage of patients with different liver diseases and their average error $\left(\mathrm{P} \pm \mathrm{m}_{\mathrm{p}}\right)$ were estimated. Significance of difference in the frequency of liver pathology in the two cohorts was determined using the Chi-square 
Table 1. The distribution of liver diseases in cohorts of HIV-infected individuals with and without antibody to Toxoplasma gondii (Nicolle et Manceaux, 1908).

\begin{tabular}{|c|c|c|c|c|c|c|c|}
\hline & \multicolumn{2}{|c|}{ T. gondii positive $(\mathrm{N}=531)$} & \multicolumn{2}{|c|}{ T. gondii negative $(\mathrm{N}=376)$} & \multicolumn{3}{|c|}{ Chi-square test } \\
\hline & Number & $\mathrm{P} \pm \mathrm{m}_{\mathrm{p}} \%$ & Number & $\mathrm{P} \pm \mathrm{m}_{\mathrm{p}} \%$ & $\chi^{2}$ & $\mathrm{p}$ & $\mathrm{C}$ \\
\hline Chronic HBV infection & 43 & $8.1 \pm 1.2$ & 25 & $6.7 \pm 1.3$ & 0.666 & 0.415 & 0.027 \\
\hline Chronic HCV infection & 50 & $9.4 \pm 1.3$ & 42 & $11.2 \pm 1.6$ & 0.743 & 0.389 & 0.029 \\
\hline Chronic HBV-HCV coinfection & $138^{*}$ & $26.0 \pm 1.9$ & 70 & $18.62 \pm 2.0$ & 6.768 & 0.010 & 0.086 \\
\hline Chronic toxic hepatitis & 8 & $1.5 \pm 0.5$ & 1 & $0.27 \pm 0.3$ & 3.449 & 0.064 & 0.062 \\
\hline Chronic cryptogenic hepatitis & 63 & $11.9 \pm 1.4$ & 35 & $9.31 \pm 1.5$ & 1.492 & 0.222 & 0.041 \\
\hline Chronic EBV-hepatitis & 2 & $0.4 \pm 0.3$ & 3 & $0.8 \pm 0.5$ & 0.712 & 0.399 & 0.028 \\
\hline Chronic CMV-hepatitis & 3 & $0.6 \pm 0.3$ & 1 & $0.3 \pm 0.3$ & 0.448 & 0.504 & 0.022 \\
\hline Total number of patients with chronic hepatitis & $307 *$ & $57.8 \pm 2.1$ & 177 & $47.1 \pm 2.6$ & 10,204 & 0.002 & 0.106 \\
\hline Liver cirrhosis, class A & 12 & $2.3 \pm 0.6$ & 6 & $1.6 \pm 0.7$ & 0.499 & 0.480 & 0.023 \\
\hline Liver cirrhosis, class B & 8 & $1.5 \pm 0.5$ & 8 & $2.1 \pm 0.7$ & 0.490 & 0.484 & 0.023 \\
\hline Liver cirrhosis, class $\mathrm{C}$ & 8 & $1.5 \pm 0.5$ & 4 & $1.1 \pm 0.5$ & 0.331 & 0.566 & 0.019 \\
\hline Total number of liver cirrhosis & 28 & $5.3 \pm 2.0$ & 18 & $4.8 \pm 1.1$ & 0.108 & 0.743 & 0.011 \\
\hline General liver pathology & $335^{*}$ & $63.1 \pm 2.1$ & 195 & $51.9 \pm 2.6$ & 11.423 & $<0.001$ & 0.112 \\
\hline
\end{tabular}

* - the difference between the indexes in cohorts of patients with and without T. gondii is statistically significant; $\chi 2$ - Pearson's chi-squared test; C Pearson's contingency coefficient; $\mathrm{P}$ - percentage; $\mathrm{m}_{\mathrm{p}}$ - standard error of percentage; $\mathrm{p}$ - statistical significance.

test (Pearson's $\chi^{2}$ test). The relationship between seropositive status for toxoplasmosis and specific liver pathology was assessed with the Pearson contingency coefficient (C). Significance of difference between the incidence of liver pathology among patients who died in a cohort, and the frequency in the whole cohort, was assessed by Student's t-test.

Our study was approved by the Ethics Commission of Ivano-Frankivsk National Medical University (Expert Decision No. 96/17 dated 24.05.2017).

\section{RESULTS}

A total of 531 individuals $(61.4 \%$ men and $38.6 \%$ women) were included in the cohort of patients-seropositive to Toxoplasma gondii and 376 individuals (53.9\% men and $46.2 \%$ women) were included in the seronegative cohort. In the seropositive cohort $91(17.1 \pm 1.6 \%)$ patients had stage I HIV infection, $101(19.0 \pm 1.7 \%)$ had stage II, $80(15.07 \pm 1.55 \%)$ had stage III, and $259(48.8$ $\pm 2.2 \%)$ had stage IV. In the seronegative cohort 48 (12.8 $\pm 1.7 \%, \mathrm{p}>0.05)$ patients had stage I of HIV-infection, $78(20.7 \pm 2.1 \%, \mathrm{p}>0.05)$ had stage II, $76(20.2 \pm 2.1 \%$, $\mathrm{p}>0.05)$ had stage III, and $174(46.3 \pm 2.6 \%, \mathrm{p}>0.05 \%)$ patients had stage IV. Therefore, the distribution of patients regarding the stage of HIV-infection was similar in both cohorts.

Antiretroviral therapy (ART) was received by 352 patients in the seropositive cohort $(66.3 \pm 2.05 \%)$ and by 287 patients in the seronegative cohort $(76.3 \pm 2.2 \%, \mathrm{p}=$ 0.002).

Sulfamethoxazole/trimethoprim $(400 / 80 \mathrm{mg}$ twice daily) for the prevention of Pneumocystis pneumonia was given to 134 patients $(25.2 \pm 1.9 \%)$ in the seropositive cohort, and 88 patients $(23.4 \pm 2.2 \%, \mathrm{p}>0.05)$ in the seronegative cohort. Azithromycin (1,200 mg once a week) for the prevention of the Mycobacterium avium complex infection was given to 50 patients $(9.4 \pm 1.3 \%)$ in the seropositive cohort and 34 patients $(9.0 \pm 1.5 \%, \mathrm{p}>0.05)$ in the seronegative cohort. Therefore, sulfamethoxazole/ trimethoprim and azithromycin were taken by the same proportion of patients in these two cohorts.
In the seropositive cohort 58 patients $(10.9 \pm 1.4 \%)$ had signs of active $T$. gondii infection and 51 patients had signs of activation of endogenous $T$. gondii infection (either the titre of IgG increasing by more than twice (46 patients) or the appearance of IgM following the previous presence of IgG (five patients). Seven patients had primary $T$. gondii infection with seroconversion, either the appearance of $\operatorname{IgM}$ followed by the appearance of $\operatorname{IgG}$ after 3-4 weeks (one person) or the initial appearance of $\operatorname{IgG}$ without $\operatorname{IgM}$ (six people).

There were 24 patients seropositive to T. gondii who had a diagnosis of toxoplasmic encephalitis. In addition, toxoplasmosis of the brain was diagnosed in three patients of the seronegative cohort because of the primary infection. Antibodies to $T$. gondii subsequently appeared in two of the patients who were moved to the seropositive cohort. The third patient remained seronegative without any specific antibodies in the blood until her death 15 days later (the patient remained in the seronegative cohort).

There were 49 people with serological signs of active toxoplasmosis. They had a moderate increase in liver and spleen (hepatolienal syndrome) which significantly exceeded the frequency of symptoms in the whole seropositive cohort $(84.48 \pm 4.75 \%$ against $63.1 \pm 2.1 \%, t=4.1, p$ $<0.001)$. The average level of ALT in the group of patients with serological signs of activity was insignificantly higher than the level in the entire cohort at the initial examination $(102.2 \pm 11.4 \%$ against $77.3 \pm 9.8 \%, \mathrm{t}=1.7, \mathrm{p}=0.0986)$.

Diseases (hepatitis and cirrhosis from every cause) were observed in 530 out of 907 patients examined (58.4 $\pm 1.6 \%$ ). However, according to the data presented in Table 1, the frequency of liver pathologies was distributed unequally between the two cohorts with more among seropositive patients $(63.1 \pm 2.1 \%)$ than among seronegative ones $(51.9 \pm$ $2.6 \%), p<0.001$. The total number of patients with chronic hepatitis from all etiological factors (HBV infection, $\mathrm{HCV}$ infection, HBV-HCV coinfection, herpesviruses, toxic and cryptogenic origin) was higher in the seropositive cohort than in the seronegative cohort $(57.8 \pm 2.14 \%$ and $47.1 \pm$ $2.6 \%$, respectively, $\mathrm{p}=0.002$ ) but only chronic HBV-HCV 
Table 2. The distribution of liver diseases in deceased HIV-infected patients out of cohorts with and without antibody to Toxoplasma gondii (Nicolle et Manceaux, 1908)

\begin{tabular}{|c|c|c|c|c|c|c|c|}
\hline & \multicolumn{2}{|c|}{ T. gondii positive $(\mathrm{N}=71)$} & \multicolumn{2}{|c|}{ T. gondii negative $(\mathrm{N}=48)$} & \multicolumn{3}{|c|}{ Chi-square test } \\
\hline & Number & $\mathrm{P} \pm \mathrm{m}_{\mathrm{p}} \%$ & Number & $\mathrm{P} \pm \mathrm{m}_{\mathrm{p}} \%$ & $\chi^{2}$ & $\mathrm{p}$ & $\mathrm{C}$ \\
\hline Chronic HBV infection & 4 & $5.6 \pm 2.7$ & 5 & $10.4 \pm 4.4$ & 0.937 & 0.334 & 0.089 \\
\hline Chronic HCV infection & 6 & $8.5 \pm 3.3$ & 7 & $14.6 \pm 5.1$ & 1.107 & 0.293 & 0.096 \\
\hline Chronic HBV-HCV coinfection & $22 *$ & $31.0 \pm 5.5$ & 7 & $14.6 \pm 5.1$ & 4.181 & 0.041 & 0.187 \\
\hline Chronic toxic hepatitis & 10 & $14.1 \pm 4.1$ & 6 & $12.5 \pm 4.8$ & 0.062 & 0.804 & 0.023 \\
\hline Chronic cryptogenic hepatitis & 5 & $7.0 \pm 3.0$ & 5 & $10.4 \pm 4.4$ & 0.424 & 0.516 & 0.084 \\
\hline Chronic EBV-hepatitis & 1 & $1.4 \pm 1.4$ & 1 & $2.1 \pm 2.1$ & 0.079 & 0.779 & 0.026 \\
\hline Chronic CMV-hepatitis & 1 & $1.4 \pm 1.4$ & 1 & $2.1 \pm 2.1$ & 0.079 & 0.779 & 0.026 \\
\hline Liver cirrhosis & 17 & $23.9 \pm 5.1$ & 5 & $10.4 \pm 4.4$ & 3.477 & 0.063 & 0.168 \\
\hline General liver pathology & $66^{*}$ & $93.0 \pm 3.0$ & 37 & $77.1 \pm 6.1$ & 6.201 & 0.013 & 0.228 \\
\hline
\end{tabular}

* - the difference between the indexes in cohorts of patients with and without T. gondii is statistically significant;

$\chi^{2}$ - Pearson's chi-squared test; C - Pearson's contingency coefficient; $\mathrm{P}$ - percentage; $\mathrm{m}_{\mathrm{p}}$ - standard error of percentage; $\mathrm{p}$ - statistical significance.

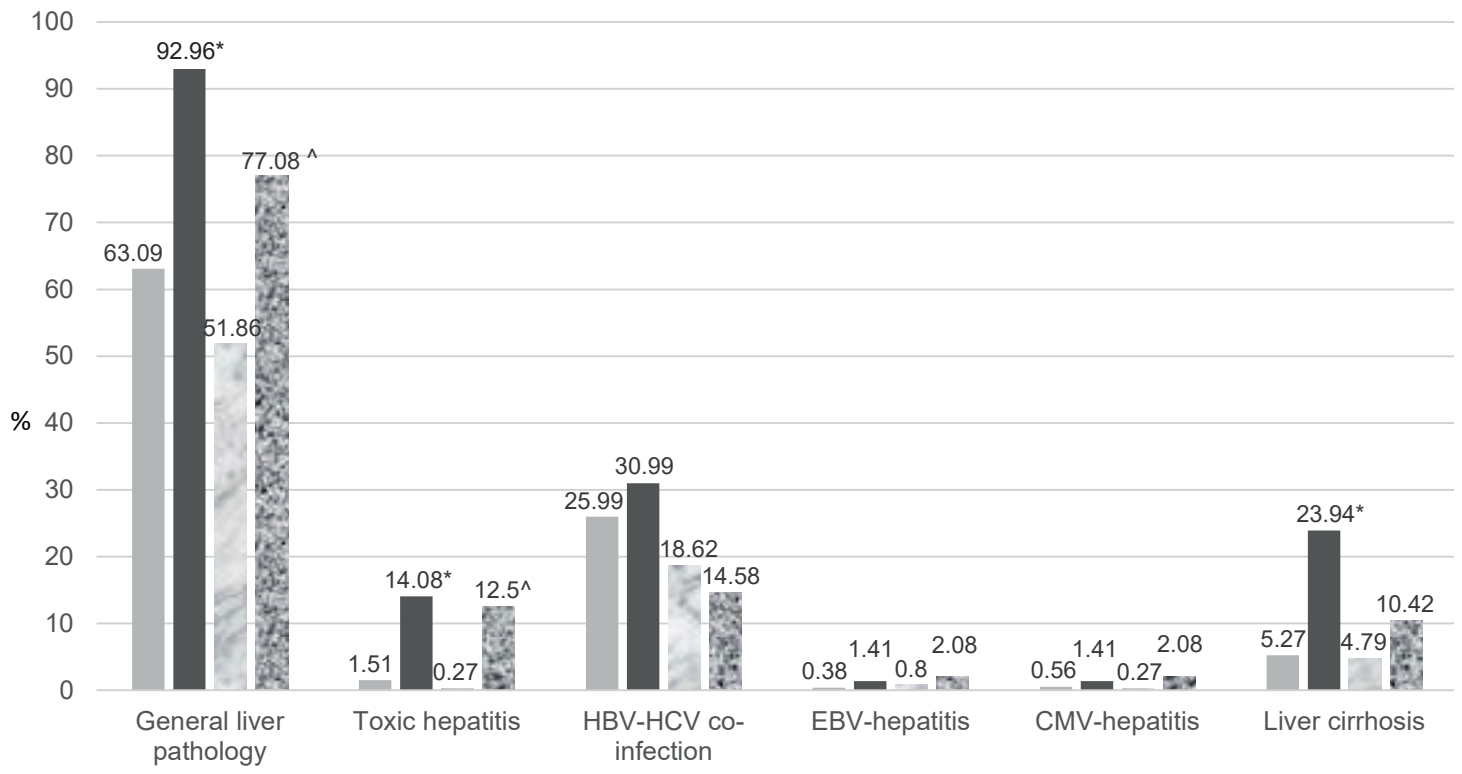

Seropositive patients to toxoplasmosis: all patients in cohort, $\mathrm{n}=531$

- Seropositive patients to toxoplasmosis: deceased patients out of cohort, $n=71$

Seronegative patients to toxoplasmosis: all patients in cohort, $\mathrm{n}=376$

Seronegative patients to toxoplasmosis: deceased patients out of cohort, $n=48$

Fig. 1. Frequency of different liver pathologies in deceased patients from cohorts seropositive and seronegative to Toxoplasma gondii (Nicolle et Manceaux, 1908).

* - difference between the indices for the entire cohort of seropositive patients and for the group of deceased patients from this cohort $(\mathrm{p}<0.05) ;^{\wedge}-$ difference between the indices for the entire cohort of seronegative patients and for the group of deceased patients from this cohort $(\mathrm{p}<0.05)$

coinfection was significantly greater $(26 \pm 1.9 \%$ and 18.6 $\pm 2.0 \%$, respectively, $\mathrm{p}=0.010$ ).

In both cohorts, the incidence of liver cirrhosis was the same. Contingency of the liver pathology with seropositivity to $T$. gondii was in most cases very low in the patients with each separate diagnosis and showed the independence of these two types of diseases. However, there were weak associations between infection with $T$. gondii and the total number of chronic hepatitis cases $(\mathrm{C}=0.106)$ and the total number of patients with liver diseases $(C=0.112)$. The frequency of liver cirrhosis in both cohorts did not differ (see Table 1).

According to ALT activity at initial examination in 307 seropositive patients with chronic hepatitis from any cause there was minimal activity of hepatitis in 275 patients $(89.58 \pm 1.74 \%)$, mild activity - in $25(8.1 \pm 1.6 \%)$ and moderate activity in seven patients $(2.6 \pm 0.9 \%)$. At the same time, among 177 seronegative patients with chronic hepatitis from any cause, there was minimal activity in 167 individuals $(94.4 \pm 1.7 \%)$, mild activity in nine patients $(5.1 \pm 1.7 \%)$ and moderate activity in one patient $(0.56 \pm$ $0.56 \%$ ). Therefore, there was no significant difference in hepatitis activity between these two cohorts $(p>0.05)$.

A total of 119 patients died during the three years, 71 from the seropositive cohort $(13.4 \pm 1.5 \%)$ and 48 from the seronegative cohort $(12.8 \pm 1.7 \%)$. The mortality rate did not differ between the two cohorts $(p>0.05)$. The causes of death were a variety of severe 
opportunistic diseases including tuberculosis in 36 patients, meningoencephalitis (of different origins) in 23 patients, including toxoplasmosis - in five patients, bacterial lung destruction in two patients and oncology diseases in two patients (Kaposi's sarcoma in one, nonHodgkin lymphoma in the other). Decompensated liver cirrhosis as the cause of death was in 22 patients.

According to the data in Table 2, the general liver pathology in deceased patients was more common in seropositive individuals than in seronegative ones $(93.0 \pm 3.04 \%$ and $77.1 \pm 6.1 \%$, respectively, $\mathrm{p}=0.013)$. Chronic HBV$\mathrm{HCV}$ coinfection was twice as common in the seropositive cohort than in the seronegative cohort $(31.0 \pm 5.5 \%$ and $14.6 \pm 5.1 \%$, respectively, $\mathrm{p}=0.041)$. In deceased patients the frequency of liver cirrhosis showed an insignificant increase in the seropositive cohort $(23.9 \pm 5.1 \%$ and $10.4 \pm$ $4.4 \%$, respectively, $\mathrm{p}=0.063$ ).

In deceased patients there were weak associations between seropositivity to T. gondii and chronic HBV-HCV coinfection $(C=0.187)$, liver cirrhosis $(C=0.168)$ and the general liver pathology $(\mathrm{C}=0.228)$ (see Table 2$)$. The activity of hepatitis, regardless of etiology, was minimal in both deceased seropositive patients and deceased seronegative patients, except one with cryptogenic hepatitis who had pronounced activity with ALT activity 16-fold higher than the upper limit of the normal level $(658 \mathrm{U} / \mathrm{ml})$. Thus, no significant difference of hepatitis activity was observed between cohorts.

Among deceased patients seropositive to $T$. gondii the number with total liver pathologies increased by $30 \%$ compared to the entire seropositive cohort $(92.96 \pm 3.04 \%$ and $63.09 \pm 2.09 \%$, respectively, $\mathrm{t}=8.1, \mathrm{p}<0.0001)$. The number of patients with toxic hepatitis was 9.3-fold higher $(14.08 \pm 4.13$ and $1.51 \pm 0.53$, respectively, $\mathrm{t}=3.02, \mathrm{p}$ $=0.0026$ ). For deceased patients with cirrhosis it was 4.5 times higher $(23.94 \pm 5.06$ and $5.27 \pm 1.97$, respectively, $t$ $=3.44, \mathrm{p}=0.0006$ ), (see Fig. 1).

Among the deceased seronegative patients, general liver pathology increased by $25 \%$ compared to the total seronegative cohort $(77.08 \pm 6.07$ and $51.86 \pm 2.58$, respectively, $t$ $=3.82, \mathrm{p}=0.00015)$ due to the increase of the proportion of patients with toxic hepatitis $(12.50 \pm 4.77$ and $0.27 \pm$ 0.27 , respectively, $\mathrm{t}=2.56, \mathrm{p}=0.011)$. However, among seronegative deceased patients the proportion with liver cirrhosis did not increase (see Fig. 1).

\section{DISCUSSION}

This study found that $T$. gondii could have a non-specific additional impact on the development of some liver diseases. The total number of liver diseases occurred more often in seropositive individuals than in seronegative ones. This can be explained by the negative influence of $T$. gondii on liver parenchyma. In the literature there are reports of the development of disorders of basic metabolic processes in mouse cells under the influence of $T$. gondii. This parasite is able to block the peroxisome of proliferator-activated receptors of the host cells and through this mechanism to suppress the activity of many genes participating in the metabolism of xenobiotics, fatty acids and lipids, it can weak- en the mitochondrial respiratory chain in mice liver cells (He et al. 2016). Due to negative reprogramming of metabolism of liver cells, the toxic effects of medicines, alcohol and other chemical compounds might be increased. Toxoplasma gondii can affect liver cells not only independently but also through the mechanism of cytokine imbalance (increased level of pro-inflammatory cytokines, especially INF- $\gamma$, TNF- $\alpha$, IL-12) (Masek and Hunter 2013).

The increased frequency of HBV-HCV coinfection in seropositive to $T$. gondii individuals has remained without proper explanation. However, it is known that the parasite is able to contributes to the replication of $\mathrm{HCV}$ and also contribute to its chronisation (Nagwa et al. 2016). On the other hand, HCV infection has been shown to promote the reactivation of latent toxoplasmosis (El-Nahas et al. 2014, Nagwa et al. 2016).

HBV-HCV coinfection in seropositive to $T$. gondii persons more common than in seronegative ones, that probably indicated on a high risk of infection through injection drug using or sexual abuse with traumatisation of mucous membranes or neglecting the contact with menstrual blood, tattoo practice, etc. It could be assumed that such risky behavior of some patients is stimulated by T. gondii, which persists in the brain and it is able to do remodelling of the human mental health (Flegr et al. 2002, Lafferty 2006, Flegr 2007).

In patients with a fatal outcome, the general liver pathology as well as the frequency of toxic hepatitis increased in each cohort regardless of their serological status. Here T. gondii had a little importance because of low coefficient of contingency with general liver pathology $(C=0.228)$. Chronic HBV-HCV coinfection was more common in the seropositive cohort than in the seronegative cohort as it was found both in entire cohorts and in deceased patients. T. gondii had a weak role in distributing HBV-HCV coinfection among died individuals $(\mathrm{C}=0.187)$. Also, a liver cirrhosis was more common in seropositive deceased patients than in seronegative, and in them $T$. gondii is weakly involved in a formation of cirrhosis $(\mathrm{C}=0.168)$.

These findings are important for healthcare workers because they indicate the necessity for the diagnosis and treatment of active infection with T. gondii in HIV-positive individuals with liver diseases.

However the results of the present study may have been influenced by the higher percentage of patients receiving ART in the seronegative cohort than in the seropositive cohort. The use of prophylactic doses of biseptol (sulfamethoxazole/trimethoprim) and azithromycin in patients with low CD4+ T-lymphocyte counts could prevent infection or reactivation of $T$. gondii. Although the same number of people in both cohorts received these medicines, the duration of and their compliance to the treatment could be different.

In conclusion, in HIV-infected patients, T. gondii is a weak non-specific additional factor that supports the inflammatory process in the liver and the progression of liver cirrhosis, regardless of their etiology and the degree of activity, but does not influence the degree of hepatitis activity. The increased prevalence of chronic HBV-HCV 
co-infection in $T$. gondii carriers may be related to their risk factor behaviour towards uncontrolled blood-borne infections.
Acknowledgements. We would like to thank the doctors, nurses, and other medical staff of Ivano-Frankivsk Regional Center for AIDS Prevention and Fight for their professional assistance through-out the study.

\section{REFERENCES}

Alvarado-Esquivel C., Torres-Berumen J.L., Estrada-Martínez S., Liesenfeld O., Mercado-Suarez M.F. 2011: Toxoplasma gondii infection and liver disease: a case-control study in a northern Mexican population. Parasit. Vectors 4 : 75.

Atilla A., Aydin S., Demirdöven A.N., Kilic S.S. 2015: Severe toxoplasmic hepatitis in an immunocompetent patient. Jpn. J. Infect. Dis. 68: 407-409.

Bonacini M., Kanel G., Alamy M. 1996: Duodenal and hepatic toxoplasmosis in a patient with HIV infection: review of the literature. Am. J. Gastroenterol. 91: 1838-1840.

Castellares C., Barreiro P., Martín-Carbonero L., Labarga P., Vispo M.E., Casado R., Galindo L., Garcia-Gasko P., Garcia-Samaniego J. 2008: Liver cirrhosis in HIV-infected patients: prevalence, aetiology and clinical outcome. J. Viral. Hepat. 15: 165-172.

CDC 2017: National Center for HIV/AIDS, Viral Hepatitis, STD, and TB (US). HIV and Viral Hepatitis. (Accessed 28 April, 2017) URL: https://www.cdc.gov/hiv/pdf/library_factsheets hiv and viral hepatitis.pdf

Chaddha D.S., Kalra S.P., Singh A.P., Gupta R.M., SancheTEE P.C. 1999: Toxoplasmic encephalitis in acquired immunodeficiency syndrome. J. Assoc. Physicians India 47: 680-684.

Dardé M.L., Ajzenberg D., Smith J. 2011: Population structure and epidemiology of Toxoplasma gondii. In L.M. Weiss, K. Kim (eds.), Toxoplasma Gondii: The Model Apicomplexan: Perspectives and Methods. Academic Press, Cambridge, pp. 49-80.

DoĞAn N., KabukçUoĞLu S., VArdareli E. 2007: Toxoplasmic hepatitis in an immunocompetent patient. Turkiye Parazitol. Derg. 31: 260-263.

El-Rehim El-Henavy A.A., Abdel-Razik A., Zakaria S., ElHammady D., Saudy N., Azab S.M. 2015: Is toxoplasmosis a potential risk factor for liver cirrhosis? Asian Pac. J. Trop. Med. 8: 784-791.

El-Nahas H.A., El-Tantawy N.L, Farag R.E., Alsalem A.M. 2014: Toxoplasma gondii infection among chronic hepatitis C patients: a case-control study. Asian Pac. J. Trop. Med. 7: 589-593.

FLEGR J. 2007: Effects of Toxoplasma on Human Behavior. Schizophrenia Bull. 33: 757-760.

Flegr J., Havlícek J., Kodym P., Malý M., Smahel Z. 2002. Increased risk of traffic accidents in subjects with latent toxoplasmosis: a retrospective case-control study. BMC Infect. Dis. 2: 11 .

Flegr J., Prandota J., Sovicková M., Israili Z.H. 2014: Toxoplasmosis - a global threat. Correlation of latent toxoplasmosis with specific disease burden in a set of 88 countries. PloS ONE. 9: e90203.

Furtado J.M., Smith J.R., Belfort R.JR., Gattey D., WinTHROP K.L. 2011: Toxoplasmosis: a global threat. J. Glob. Infect. Dis. 3: 281-284.

García-García C., Castillo-Álvarez F., Azcona-Gutiérrez J.M., Herraiz M.J., Ibarra V., Oteo J.A. 2015: Spinal cord toxoplasmosis in human immunodeficiency virus infection/ acquired immunodeficiency syndrome. Infect. Dis. (Lond). 47: 277-282.

Gazzinelli R., Xu Y., Hieny S., Cheever A., Sher A. 1992: Simultaneous depletion of CD4 and CD8 T-lymphocytes is required to reactivate chronic infection with Toxoplasma gondii. J. Immunol. 149: 175-180.

Goïta D., Karambe M., Dembélé J.P. , Sogoba D., Sidibe A.F., Diaby S., Cisse I.A., Fongoro S., Dao S. 2012: Cerebral toxo- plasmosis during AIDS in the infectious diseases department of Point-G Teaching Hospital, Bamako, Mali. Mali Med. 27: 47-50.

He J.-J., Ma J., Elsheikha H.M., Song H.-Q., Zhou D.-H., Zhu X.-Q. 2016: Proteomic profiling of mouse liver following acute Toxoplasma gondii infection. PLoS ONE 11: e0152022.

Huang J., Zhang H., Liu S., Wang M., Wan B., Velani B., ZHU Y., LiN S. 2018: Is Toxoplasma gondii infection correlated with nonalcoholic fatty liver disease? - A population-based study. BMC Infect. Dis. 18: 629.

Jian-Feng H., Jian-Ping X., Ru-Jin X., Chun-Yan Q. 2018: [Investigation on Toxoplasma gondii infection in liver disease patients in Hangzhou City.] Zhongguo Xue Xi Chong Bing Fang Zhi Za Zhi 30: 322-324. (In Chinese.)

Jones J.L., Kruszon-Moran D., Wilson M. McQuillan G., Navin T., McAuley J.B. 2001: Toxoplasma gondii infection in the United States: seroprevalence and risk factors. Am. J. Epidemiol. 154: 357-365.

Kung D.H., Hubenthal E.A., Kwan J.Y., Shelburne S.A., Goodman J.C., Kass J.S. 2011: Toxoplasmosis myelopathy and myopathy in an AIDS patient: a case of immune reconstitution inflammatory syndrome? Neurologist 17: 49-51.

LAFFERTy K.D. 2006: Can the common brain parasite, Toxoplasma gondii, influence human culture? Proc. R. Soc. B., Biol Sci. 273: 2749-2755.

Lang Z.W., Dao W.B., Zhang F.J., Shi X.H., Ma Z.C., Ma P.Q., SHEN B., LÜ H.B. 2005: [A pathological study on liver tissues of patients with HIV infection.] Zhonghua Gan Zang Bing Za Zhi. 13: 930-932. (In Chinese.)

LyTVYNENKo M.V. 2007: [Etiological structure and peculiarities of liver damage at HIV infection]. Patolohiya 4: 43-46. (In Ukrainian.)

Marra C.M. 2018: Central nervous system infection with Toxoplasma gondii. Handb. Clin. Neurol. 152: 117-122.

Masek K.S., Hunter CH.A. 2013: Pro-inflammatory responses in macrophages during Toxoplasma gondii infection. Madame Curie Bioscience Database[Internet]. (C) 2000-2013, Landes Bioscience. URL: https://www.ncbi.nlm.nih.gov/books/NBK5976/ (Accessed 29 April, 2017).

Montoya J.G., Liesenfeld O. 2004: Toxoplasmosis. Lancet. 363: 1965-1976.

Nadwa A.J.M., Muthear N.D. 2012: Liver function test in toxoplasmosis. Ann.Coll. Med. 38: 68-72.

Nagwa M.E.S, Manar E.R., Mohamed E.R. 2016: Toxoplasma gondii infection and chronic liver diseases: evidence of an association. Trop. Med. Infect. Dis. 1: 7.

Nunura J., Vásquez T., Endo S., Salazar D., Rodriguez A., Pereyra S., Solis H. 2010: Disseminated toxoplasmosis in an immunocompetent patient from Peruvian Amazon. Rev. Inst. Med. Trop. São Paulo. 52: 107-110.

Oksenhendler E., Charreau I., Tournerie C., Azihary M., Carbon C., Aboulker J.P. 1994: Toxoplasma gondii infection in advanced HIV infection. AIDS 8: 483-487.

Qurishi N., Kreuzberg C., Luchters G., Effenberger W., Kupfer B.., Sauerbruch T., Rockstroh J.K., Spengler U. 2003: Effect of antiretroviral therapy on liver-related mortality in patients with HIV and hepatitis $\mathrm{C}$ virus coinfection. Lancet 362: 1708-1713.

Rabaud C., May T., Amiel C., Katlama C., Leport C., AmBroise-Thomas P., CAnton P. 1994: Extracerebral toxoplasmosis in patients infected with HIV. A French National Survey. Medicine (Baltimore) 73: 306-314. 
Rodriguez-Mendez M.L., Gonzalez-Quintela A., AguilERA A., BARrio E. 2000: Prevalence, patterns, and course of past hepatitis B virus infection in intravenous drug users with HIV-1 infection. Am. J. Gastroenterol. 95: 1316-1322.

Trojan A., Kreuzer K.A., Flury R., Schmid M., Schneider J., SChröder S. 1998: Liver changes in AIDS. Retrospective analysis of 227 autopsies of HIV-positive patients. Pathologe. 19: 194-200.

VeERANOOt N. 2017: Toxoplasma gondii and HIV: a never-ending story. Lancet 4: E146-E147.

VIDAL J.E. 2019: HIV-related cerebral toxoplasmosis revisited: current concepts and controversies of an old disease. J. Int. Assoc. Provid. AIDS Care 18: 1-20.

Cite this article as: Hryzhak I.H. 2020: Infection with Toxoplasma gondii can promote chronic liver diseases in HIV-infected individuals. Folia Parasitol. 67: 034. 